\title{
SPECT/CT and PET/CT molecular imaging in medullary thyroid carcinoma. Are we running in the right direction?
}

\author{
Anna Margherita Maffione ${ }^{1} \cdot$ Francesco Giammarile $^{2}$ - Domenico Rubello ${ }^{1}$
}

Received: 6 June 2017 / Accepted: 7 June 2017 / Published online: 22 June 2017

(C) Springer-Verlag GmbH Germany 2017

We have read with interest the paper by Yamaga LYI et al. entitled ${ }^{668} \mathrm{Ga}$-DOTATATE PET/CT in recurrent medullary thyroid carcinoma: a lesion-by-lesion comparison with ${ }^{111} \mathrm{In}$ octreotide SPECT/CT and conventional imaging" published in the European Journal of Nuclear Medicine and Molecular Imaging [1]. It is focused on the comparison between different diagnostic imaging methods in order to investigate their effectiveness in localizing recurrent medullary thyroid carcinoma (MTC). Several parameters have probably biased the above study, such as the quite small patient population enrolled $(n=15)$ in this retrospective analysis and the very high serum calcitonin $(\mathrm{Ct})$ levels in post-treatment survey. These factors probably explain the excellent sensitivity values found with imaging methods, especially the nuclear medicine/molecular imaging ones in this patient series.

MTC is a rare neuroendocrine malignancy harboring from the thyroid $\mathrm{C}$ cells and, according to recent SEER (Surveillance, Epidemiology and End Results) data, accounts only for $1-2 \%$ of thyroid cancers in the USA [2]. It is scarcely or not sensitive to chemo- or external radiotherapy: at present, surgery both at initial diagnosis and in the case of recurrent tumor is the only recognized option that has the possibility to be curative [3].

'This Editorial Commentary refers to the article http://dx.doi.org/10. 1007/s00259-017-3701-9.'

Domenico Rubello

domenico.rubello@libero.it

1 Department of Nuclear Medicine, Radiology, Neuroradiology, and Clinical Pathology, Santa Maria della Misericordia Hospital, Via Tre Martiri, 140, 45100 Rovigo, Italy

2 Nuclear Medicine and Diagnostic Imaging Section, International Atomic Energy Agency, Vienna, Austria
Recurrent disease may be disclosed during follow-up of MTC patients with persistently elevated/increasing serum Ct levels or, more rarely and especially in the case of poorly differentiated and aggressive tumors, with increasing serum carcinoembryonic antigen (CEA) levels. In general, scientific communities agree that an increase in the serum $\mathrm{Ct}$ level above $150 \mathrm{pg} / \mathrm{mL}$ should prompt additional imaging in order to localize and possibly surgically remove lesions.

Immunohistochemical studies have demonstrated that MTC cells can express a wide variety of peptides on their cellular membrane. Other than Ct and CEA, also somatostatin receptors (SSTRs), neurotensin, gastrin/cholecystokinin B receptor (CCKBR), enkephalin, paratormon-releasing peptide, chromogranin A, synaptophysin, neuron-specific enolase (NSE), 1,25-dihydroxyvitamin D3 receptors, thyrosin hydroxylase, a-tubulin, and cytocheratin have been described [4]. However, these antigens and receptors are not equally expressed, but are quite variable both considering tumor by tumor and cells by cells in the same tumor. In the era of tailored medicine, this paves the way to plan the use of molecular imaging with the choice of specific radiotracers for each tumoral cell line.

Positron emission tomography (PET) and single photon emission computed tomography (SPECT) radiopharmaceuticals reflect different metabolic pathways useable to detect recurrent MTC. At present, many radiopharmaceuticals have been employed to this scope: mainly, 18F-FDG, 18FDOPA, and 68Ga-somatostatin analogs for PET imaging while 111In-Octreotide, 131I/123I-MIBG, and just to mention, but not for usage in clinical practice, 111In-CCKBR, 131I-antiCEA, 99mTc-MIBI, 99mTc-DMSA, and 99mTc-glucagonlike receptor for SPECT.

SPECT technology is older. The first appearance of the scintigraphy application on pheocromocytoma, in this case with 123I-MIBG, is dated 1984 [5] and to our knowledge, 
differently from PET, neither systematic revision nor metaanalysis studies have been conducted specifically regarding SPECT radiopharmaceuticals in large series of MTC patients.

Good values of sensitivity, specificity, and accuracy have been demonstrated on positron-emitter radiotracers: two different meta-analyses published in the same year$2012[6,7]$ - demonstrated a pooled sensitivity of $69 \%$ [6] and a detection rate of $59 \%$ for $18 \mathrm{~F}-\mathrm{FDG}$ PET [7] that was higher in patients with higher serum levels and rapid kinetic values (rapidly doubling time and increased velocity) of tumor markers (Ct and CEA); this suggested that $18 \mathrm{~F}-$ FDG could be very helpful in patients with more aggressive disease [8].

Several studies $[8,9]$ and a meta-analysis on 18F-DOPA PET revealed a detection rate of $66 \%$ (per patient) and $71 \%$ (per lesion) [10], which represents, at present, the best values achievable.

Considering the higher resolution of PET versus SPECT technology and the affinity of positron-emitters compounds for a major number of SSTRs in comparison to SPECTradiocompounds, Gallium-68 labeled with somatostatinanalog peptides rapidly became the preferred radiopharmaceutical to image recurrent MTC. Reubi et al. in 2000 [11] evaluated in a pivotal study the five SSTRs affinity for many labeled and unlabeled somatostatin-like compounds revealing that even small structural modifications, as chelator substitution or metal replacement may considerably affect the binding link. This wide availability of somatostatin-like tracers is beneficial in a tumor with a well-known heterogeneous expression of somatostatin receptors [12]. In the era of theranostic, the main advantage of SSTR imaging could be the possibility to propose to the patient a tailored radionuclide therapy using 177-Lu or 90-Y-labeled somatostatin analogs [13].

In a study by Treglia et al., published in 2011, the authors investigated three PET radiopharmaceuticals, i.e. 18F-DOPA, 18F- FDG, and 68Ga-somatostatin analogs, on the same MTC population demonstrating a statistically significant difference of sensitivity and lesion detection between 18F-DOPA and the other two tracers. This confirmed that $18 \mathrm{~F}-\mathrm{DOPA}$ PET is, at present, the best option for restaging biochemical recurrent MTC $[14,15]$. These data are in agreement with those published by Marzola et al. in 2010 [8].

Despite the evidence of good sensitivity of PET tracers, international guidelines refuse to recommend their use for restaging MTC with biochemical failure. The European Thyroid Association Guidelines for metastatic MTC in 2012 recommend only the use of bone scintigraphy while the use of PET with FDG or DOPA is not advocate for its low sensitivity and costs, respectively [16].

In 2015 the American Thyroid Association (ATA), while preparing the guidelines on MTC, received the decline of endorsement by the European Association of Nuclear Medicine (EANM) Thyroid Committee due to relevant differences on the interpretation of the available scientific evidence [17]. ATA guidelines appear to consciously decrease the role of Nuclear Medicine and Molecular Imaging in spite of an increasing volume of evidence available in the literature on the usefulness of PET/CT with different positron-emitters radiocompounds.

In conclusion, considering the high genetic heterogeneity of MTC, the optimal diagnostic approach should be immunohistochemical analysis of surgical specimens and the consequent selection of adapted radiopharmaceuticals.

\section{Compliance with ethical standards}

Funding This study was not funded

Conflict of interest The authors declare they have not conflict of interest

Ethical approval Not applicable to an Editorial.

\section{References}

1. Yamaga LYI, Cunha ML, Campos Neto GC, Garcia MRT, Yang $\mathrm{JH}$, Comacho CP, et al. 68Ga- DOTATATE PET/CT in recurrent medullary thyroid carcinoma: a lesion-by-lesion comparison with 111 In-octreotide SPECT/CT and conventional imaging. Eur J Nucl Med Mol Imaging. 2017 (in press).

2. Pelizzo MR, Torresan F, Boschin IM, Nacamulli D, Pennelli G, Rubello D, et al. Early, prophylactic thyroidectomy in hereditary medullary thyroid carcinoma: a 26-year monoinstitutional experience. Am J Clin Oncol. 2015;38:508-13.

3. Quayle FJ, Moley JF. Medullary thyroid carcinoma: management of lymph node metastases. Curr Treat Options in Oncol. 2005;6: 347-54.

4. Zatelli MC, Tagliati F, Taylor JE, Rossi R, Culler MD, Degli Uberti EC. Somatostatin receptor subtypes 2 and 5 differentially affect proliferation in vitro of the human medullary thyroid carcinoma cell line. J Clin Endocrinol Metab. 2001;86:2161-9.

5. Lynn MD, Shapiro B, Sisson JC, Beierwaltes WH, Meyers LJ, Ackerman R, et al. Pheochromocytoma and the normal adrenal medulla: improved visualization with I-123 MIBG scintigraphy. Radiology. 1985;155:789-92.

6. Cheng X, Bao L, Xu Z, Li D, Wang J, Li Y. 18F-FDG-PET and $18 \mathrm{~F}-\mathrm{FDG}-\mathrm{PET} / \mathrm{CT}$ in the detection of recurrent or metastatic medullary thyroid carcinoma: a systematic review and meta-analysis. J Med Imaging Radiat Oncol. 2012;56:136-42.

7. Treglia G, Villani MF, Giordano A, Rufini V. Detection rate of recurrent medullary thyroid carcinoma using fluorine-18 fluorodeoxyglucose positron emission tomography: a meta-analysis. Endocrine. 2012;42:535-45.

8. Marzola MC, Pelizzo MR, Ferdeghini M, Toniato A, Ambrosini V, Rubello D, et al. Dual PET/CT with (18) F-DOPA and (18) F-FDG in metastatic medullary thyroid carcinoma and rapidly increasing calcitonin levels: comparison with conventional imaging. Eur J Surg Oncol. 2010;36:414-21.

9. Rubello D, Wong KK, Marzola MC, Beheshti M, Ambrosini V, Chondrogiannis $\mathrm{S}$, et al. Evolving paradigms for successful molecular imaging of medullary thyroid carcinoma. Eur J Nucl Med Mol Imaging. 2012;39:563-8. 
10. Treglia G, Cocciolillo F, Di Nardo F, Poscia A, de Waure C, Giordano A, et al. Detection rate of recurrent medullary thyroid carcinoma using fluorine-18 Dihydroxyphenylalanine positron emission tomography: a meta-analysis. Acad Radiol. 2012;19:1290-9.

11. Reubi JC, Schär JC, Waser B, Wenger S, Heppeler A, Schmitt JS, et al. Affinity profiles for human somatostatin receptor subtypes SST1-SST5 of somatostatin radiotracers selected for scintigraphic and radiotherapeutic use. Eur J Nucl Med. 2000;27:273-82.

12. Rapotti M, Kumar U, Volante M, Pecchioni C, Patel YC. Immunohistochemical detection of somatostatin receptor types 15 in medullary carcinoma of the thyroid. Clin Endocrinol. 2001;54: 641-9.

13. Salavati A, Puranik A, Kulkarni HR, Budiawan H, Baum RP. Peptide receptor radionuclide therapy (PRRT) of medullary and Nonmedullary thyroid cancer using radiolabeled somatostatin analogues. Sem Nucl Med. 2016;46:215-24.

14. Treglia G, Castaldi P, Villani MF, Perotti G, de Waure C, Filice A, et al. Comparison of 18F-DOPA, 18F-FDG and 68Ga-somatostatin analogue PET/CT in patients with recurrent medullary thyroid carcinoma. Eur J Nucl Med Mol Imaging. 2012;39:569-80.

15. Slavikova K, Montravers F, Treglia G, Kunikowska J, Kaliska L, Vereb $\mathrm{M}$, et al. What is currently the best radiopharmaceutical for the hybrid PET/CT detection of recurrent medullary thyroid carcinoma? Curr Radiopharm. 2013;6:96-105.

16. Schlumberger M, Bastholt L, Dralle H, Jarzab B, Pacini F, Smit JW. And the European thyroid association task force. 2012 European thyroid association guidelines for metastatic medullary thyroid cancer. Eur Thyroid J. 2012;1:5-14.

17. Treglia G, Aktolun C, Chiti A, Frangos S, Giovanella L, Hoffmann $\mathrm{M}$, and the EANM Thyroid Committee. The 2015 revised American Thyroid Association guidelines for the management of medullary thyroid carcinoma: the "evidence-based" refusal to endorse them by EANM due to the "not evidence-based" marginalization of the role of nuclear medicine. Eur J Nucl Med Mol Imaging. 2016;43:1486-90. 